\title{
Correction to: First look at the five-factor model personality facet associations with sensory processing sensitivity
}

\author{
Anne Sophie Bröhl ${ }^{1}$ (D) $\cdot$ Karla Van Leeuwen ${ }^{2} \cdot$ Michael Pluess $^{3} \cdot$ Filip De Fruyt ${ }^{4} \cdot$ Margot Bastin $^{1} \cdot$ Sofie Weyn ${ }^{1}$. \\ Luc Goossens $^{1} \cdot$ Patricia Bijttebier ${ }^{1}$
}

(C) Springer Science+Business Media, LLC, part of Springer Nature 2021

\section{Correction: Current Psychology (2020) \\ https://doi.org/10.1007/s12144-020-00998-5}

The original version of this article unfortunately contained a mistake, parts of Study 1 and 2 sections have been omitted and mixed. Thus, this erratum is presented to fix this error.

The original article has been corrected.

Publisher's Note Springer Nature remains neutral with regard to jurisdictional claims in published maps and institutional affiliations.

The online version of the original article can be found at https://doi.org/ $10.1007 / \mathrm{s} 12144-020-00998-5$

Anne Sophie Bröhl

annesophie.broehl@kuleuven.be

Karla Van Leeuwen

karla.vanleeuwen@kuleuven.be

Michael Pluess

m.pluess@qmul.ac.uk

Filip De Fruyt

filip.defruyt@ugent.be

Margot Bastin

margot.bastin@kuleuven.be

Sofie Weyn

sofie.weyn@kuleuven.be
Luc Goossens

luc.goossens@kuleuven.be

Patricia Bijttebier

patricia.bijttebier@kuleuven.be

1 School Psychology and Development in Context, KU Leuven, Tiensestraat 102, 3000 Leuven, Belgium

2 Parenting and Special Education, KU Leuven, Vanderkelenstraat 32, 3000 Leuven, Belgium

3 School of Biological and Chemical Science, Queen Mary University of London, Mile End Road, London E1 4NS, UK

4 Developmental, Personality and Social Psychology, Ghent University, Henri Dunantlaan 2, 9000 Ghent, Belgium 